\title{
EB Resist Materials Consist of
}

\section{Catechol Derivatives}

\author{
Naoko Kihara, Satoshi Saito,Tohru Ushirogouchi, \\ and Makoto Nakase \\ Materials and Devices Research Laboratories, Toshiba Corporation, \\ 1, Komukai Toshiba-cho, Saiwai-ku, Kawasaki 210, Japan
}

Keywords: resist, calixarenes, cyclic oligomers

High-resolution resists are required for fabrication of highly integrated circuit pattern. Several studies indicate that the materials which have low molecular weight and narrow molecular weight distribution may be suitable for fabrication of a fine pattern[1]. Recently, cyclic oligomers of phenols have been investigated with a view to applying them as high-resolution resist materials.

p-Alkylcalix[6]arenes which are prepared from p-alkyl phenols and aldehydes have been evaluated as negative tone EB resist materials [2]. However p-alkylcalix[6]arenes are insoluble in aqueous alkaline solution and only sparingly soluble in organic solvents. To solve these problems, Nakamura et al. investigated calix[4]resorcinarene, which has good solubility for organic solvents and an aqueous alkaline solution, with a view to applying it as a negative tone resist material with a photoacid generator and a crosslinker [3]. They also reported a positive working resist using calix[4]resorcinarene and DNQ compound [4].

The authors are interested in hexahydroxycyclotribenzylene (HCB) which is a cyclic origomer, consisting of three dihydroxybenzylenes. As shown in Scheme 1, a remarkable structure of HCB is that the hydroxyl groups of HCB are located outside the ring. Considering this structure, HCB is expected to have a good alkaline solubility.

In this paper, the authors report the potential of HCB derivative as an aqueous alkaline soluble resist material. As a first step, the authors evaluated the positive tone performance of $\mathrm{HCB}$

3<smiles>COc1ccccc1OC</smiles><smiles>COc1cc2c(cc1OC)Cc1cc(OC)c(OC)cc1Cc1cc(OC)c(OC)cc1C2</smiles>

CTV<smiles>Oc1cc2c(cc1O)Cc1cc(O)c(O)cc1Cc1cc(O)c(O)cc1C2</smiles><smiles>[R20]c1cc2c(cc1[R20])Cc1cc([R20])c([R20])cc1Cc1cc([R20])c([R])cc1C2</smiles>

HCB-t-BoC

Scheme 1 
using a chemically amplified system.

The synthetic scheme is shown in Scheme 1 [5]. Cycrotriveratrylene (CTV) was synthesized from veratriol with formaldehyde in concentrated hydrochloric acid. The demethylation of CTV was carried out by using boron tribromide to form HCB. A t-Boc derivative of HCB was prepared using the method described in the literature[6]. Although it was impossible to form a film on a substrate by HCB alone, a thin film was obtained using HCB-t-Boc.

The acid generator utilized was triphenylsulfonium triflate (TPS-OTf), and the resist solvent was methoxy methyl propionate (MMP).

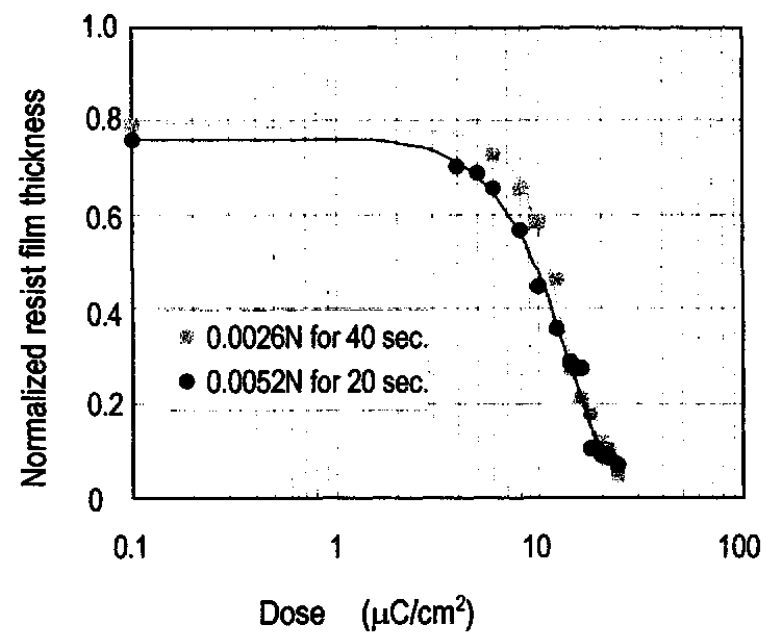

Fig. 1 Exposure characteristics of resist Acceleration voltage: $50 \mathrm{keV}$ PEB: at $100^{\circ} \mathrm{C}$ for $90 \mathrm{sec}$.

Development: in AD-10 1/100 diluent for $40 \mathrm{sec}$.

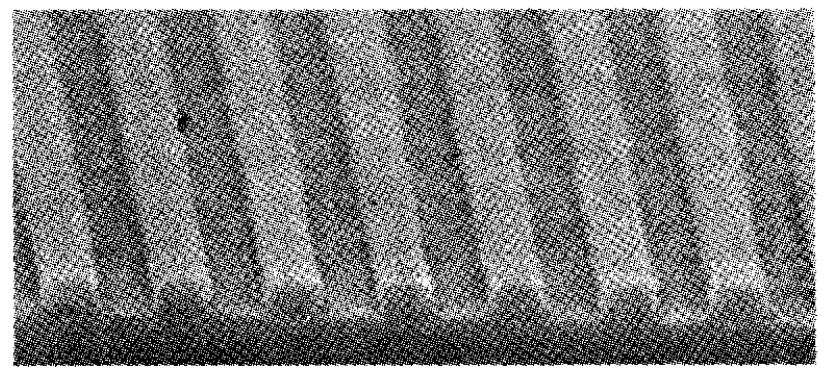

$0.5 \mu \mathrm{m}$ L\&S

Fig. 2 SEM photograph of resist pattern profile Dose: $24 \mathrm{mC} / \mathrm{cm}^{2}$

PEB: at $100^{\circ} \mathrm{C}$ for $90 \mathrm{sec}$.

Development: in $0.0026 \mathrm{~N}$ developer for $40 \mathrm{sec}$.
The resist utilized in this experiment was prepared as follows: $400 \mathrm{mg}$ of HCB-t-Boc and $6.0 \mathrm{mg}(1.5$ wt \%) of TPS-OTf were dissolved in $2.7 \mathrm{~g}$ of MMP. After filtration, the resist solution was spin-coated onto silicon wafers and baked on a hot plate at 100 ${ }^{\circ} \mathrm{C}$ for $60 \mathrm{sec}$.

EB exposure was carried out by using EX-8D (50 keV accelerating voltage, Toshiba Corp.). After the post-exposure-baking process (PEB: at $100{ }^{\circ} \mathrm{C}$ for $90 \mathrm{sec}$.), the resist film was developed in a dilute solution of aqueous base developer (AD-10: $2.38 \%$ tetramethyl ammonium hydroxide aqueous solution from Tama Chemicals Co., Ltd.).

In Fig. 1 the characteristic curves of the resist are shown. The resist film was dissolved in a dilute solution of AD-10. As shown in this figure, the positive tone property of the resist was observed. When a $0.0026 \mathrm{~N}$ dilute solution was used as a developer, the $\gamma$ value was higher than in the case that a $0.0052 \mathrm{~N}$ developer was used.

Figure 2 shows the $0.5 \mu \mathrm{m}$ line and space resist pattern profile. These experimental results indicate the HCB derivatives have the potential to be applied as high-resolution resist materials.

\section{References}

1. J. Yamamoto, S. Uchino, T. Yoshimura, H. Ohta, F. Murai, The 44th Spring Meeting of JSAP (1997) 28p-X 6, H. Shiraisi, T. Yoshomura, T. Sakamizu, T. Ueno, S. Okazaki, J. Vac. Sci. Technol. B12 (1994) 3895, S. Manako, J. Fujita, Y. Ochiai, E. Nomura, S. Matsui, Jpn. J. Appl. Phys. 36 (1997) 7773.

2. J. Fujita, Y. Ohnishi, Y. Ochiai, E. Nomura, S. Matsui, J. Vac. Sci. Technol., B14, (1996) 4272.

3. T Nakayama, K. Haga, O. Haga, M. Ueda, Chem. Lett. (1997) 295.

4. D. Takahashi, T. Nakamura, M. Ueda, Proc. of 6th SPSJ International Polymer Conference (1997) 103, 208.

5. A. S. Lindsey, J. Chem. Soc. (1965) 1685.

6. N. Kihara, T. Ushirogouchi, T. Tada, T. Naito, S. Saito, M. Nakase, J. Electrochem. Soc., 141 (1994) 3162. 